\title{
Characterization of Mixed Syngeneic-Allogeneic and Syngeneic-Xenogeneic Islet-Graft Rejections in Mice \\ Evidence of Functional Impairment of the Remaining Syngeneic Islets in Xenograft Rejections
}

Olle Korsgren and Leif Jansson

Department of Medical Cell Biology, Uppsala University, S-751 23 Uppsala, Sweden

\begin{abstract}
Allogeneic mouse islets or xenogeneic rat islets, or fetal porcine islets were implanted under the renal capsule of C57BL/6 mice either alone or carefully mixed with syngeneic islets. With this experimental model the syngeneic islets, although not rejected themselves, are exposed to cytokines and inflammatory mediators released during either allograft or xenograft rejection. No differences in insulin content could be observed between mixed islet grafts and pure syngeneic islet grafts 6 wk after transplantation. Neither was there any morphological evidence of a nonspecific destruction of syngeneic islets. These findings suggest that the mechanisms of both allograft and xenograft rejections are highly specific. The hormone release from the mixed syngeneic-allogeneic grafts was similar to that from pure syngeneic islet grafts. In contrast, a pronounced impairment of both the first and second phases of insulin release was observed 2 wk after implantation in mixed syngeneic-xenogeneic islet grafts. When perfusing the mixed islet graft after completed rejection of the concordant xenogeneic rat islets ( 6 wk after implantation), the insulin release from the remaining syngeneic mouse islets was identical to that of control grafts. However, syngeneic mouse islets exposed to the rejection mechanism of the discordant xenogenic pig islet-like cell clusters did not attain a complete functional recovery. (J. Clin. Invest. 1994. 93:11131119.) Key words: transplantation • rejection • islets of Langerhans $\bullet$ cytokines $\bullet$ insulin release
\end{abstract}

\section{Introduction}

The immune response to allogeneically or xenogeneically transplanted tissues comprises both specific and nonspecific components. The latter mainly consists of the inflammatory reaction inflicted by the surgical injury associated with implantation. The specific allograft reaction, on the other hand, depends on an activation of both $\mathrm{CD}^{+}$and $\mathrm{CD} 8^{+} \mathrm{T}$ lymphocytes (1). Both indirect and direct pathways of antigen presentation can stimulate activation and proliferation of alloreactive T lymphocytes directed against pancreatic islets (2). During these processes, a large number of cytokines are released, which not only recruit immunocompetent cells into the graft, but also directly contribute to cell damage ( 3 ).

Address correspondence to Dr. Olle Korsgren, Department of Medical Cell Biology, Biomedical Center, PO Box 571, S-751 23 Uppsala, Sweden.

Received for publication 26 July 1993 and in revised form 1 November 1993.

J. Clin. Invest.

(c) The American Society for Clinical Investigation, Inc.

$0021-9738 / 94 / 03 / 1113 / 07 \quad \$ 2.00$

Volume 93, March 1994, 1113-1119
The predominant cell mediating xenogeneic cellular immune responses is probably the $\mathrm{CD} 4^{+} \mathrm{T}$ lymphocyte. This concept is based on the findings that mice treated with an anti-CD4 antibody do not reject xenogeneic skin (4) or islet grafts (5), whereas $\mathrm{CD}^{+} \mathrm{T}$ cell depletion before transplantation was virtually without any beneficial effect on graft survival. Immunosuppressive drugs that inhibit lymphocyte function or proliferation, can readily prevent allograft rejection, whereas they are unable to affect rejection of a cellular xenograft (6). This discrepancy implies that different cellular mechanisms are operative in allograft or xenograft rejections, respectively $(7,8)$.

Cytokines, especially IL-1 and TNF, are known to impair islet $\beta$ cell function in vitro, and to ultimately cause cell death (9). Based on these observations, it has been proposed that cytokines released from activated macrophages within the pancreatic islets may cause a progressive $\beta$ cell destruction, finally leading to insulin-dependent diabetes mellitus (IDDM) ${ }^{1}(10)$. However, this notion has been difficult to verify in vivo, since direct effects exerted by the cytokines are impossible to separate from effects induced by the immunocompetent cells. However, one possible model has been recently described by Sutton and co-workers, who used mixed syngeneic-allogeneic islet grafts (11). They concluded that there was an absolute specificity of the allograft rejection within the mixed islet grafts, without any associated destruction of the syngeneic islets. However, no functional evaluation of the remaining syngeneic islets was performed.

The aim of the present investigation was to study the specificity of both allograft and xenograft rejections. The experimental model with mixed islet-grafts may also show if cytokines released in vivo in the very close vicinity of the remaining syngeneic islets can induce a functional impairment similar to that observed in early phases of IDDM. For this purpose, syngeneic mouse islets were either transplanted alone, or carefully mixed with either allogeneic mouse islets or xenogeneic rat or fetal porcine islets. The functional capacity of the mixed islet grafts was characterized by perfusing the islet graft-bearing kidney, either during or after rejection. Insulin extractions and immunohistology were used for quantitative analysis of surviving islet $\beta$ cells.

The specificity of both concordant and discordant xenograft rejections was found to equal that seen in allografts. However, the mechanisms mediating the xenograft rejection exerted an inhibitory effect on the glucose-stimulated insulin release from the remaining syngeneic mouse islets, which was not seen during allograft rejection. This effect is most likely mediated by products released from activated macrophages, and it resembles the impairment of $\beta$ cell function seen in early phases of IDDM. Furthermore, the finding that syngeneic islets

1. Abbreviations used in this paper: BKs, B6 and C57/Ks (mice); ICC, islet-like cell clusters; IDDM, insulin-dependent diabetes mellitus. 
mixed with discordant xenogeneic porcine islets showed permanent functional impairment, whereas the syngeneic islets could recover completely when mixed with concordant xenogeneic rat islets, may indicate that xenogeneic rejections depend also on the phylogenetic disparity between donor and recipient species.

\section{Methods}

Animals. Male inbred C57BL/6 (B6) mice, 3-5 mo old, served as recipients in all experiments with the exception of group $E$ (see below), where athymic B6 nu/nu mice (Bomholdtgaard, Ry, Denmark) were used. Male and female inbred B6 and C57BL/Ks (BKs) mice bred at the Biomedical Center (Uppsala, Sweden), originally obtained from the Jackson Laboratory (Bar Harbor, ME), 3-5 mo old, were used as syngeneic and allogeneic islet donors. Male Sprague-Dawley rats from a local breeding colony at the Biomedical Center, weighing $\sim 300 \mathrm{~g}$, were used to obtain rat islets for concordant xenogeneic transplantations. Fetal pigs served as donors for the discordant xenogeneic implantations. The pregnant sows were bred by a local farmer and were killed by means of a slaughtering mask on day $70 \pm 5$ of pregnancy (term is $115 \mathrm{~d})$. The fetuses were collected from the uterus, placed on ice, and transported to the laboratory. Porcine islet-like cell clusters were then prepared as described below. All rodents had free access to tap water and pelleted food (type R34; AB AnalyCen, Lidköping, Sweden) throughout the experimental period.

Islet isolation and transplantation. Pancreatic islets from rodents were prepared by a collagenase (Boehringer Mannheim, Boehringer, Germany) digestion method (12). Groups of $\sim 75$ mouse or rat islets were cultured free-floating for periods of either 1-2 d (mouse) or 4-5 d (rat) in medium RPMI 1640 (Flow Laboratories, Irvine, United Kingdom) supplemented with $10 \%$ (vol/vol) calf serum (Statens Bakteriologiska Laboratorium, Stockholm, Sweden). The culture dishes were kept at $37^{\circ} \mathrm{C}$ in a gas phase consisting of $5 \% \mathrm{CO}_{2}$ in humidified air, and the culture medium was changed every second day.

Preparation and culture of fetal porcine pancreas has been described in detail (13). Briefly, the pancreatic glands were minced into fragments with a size of $1-2 \mathrm{~mm}^{3}$. After $\sim 10 \mathrm{mg} / \mathrm{ml}$ collagenase digestion (Boehringer Mannheim) during simultaneous vigorous shaking at $37^{\circ} \mathrm{C}$ for $8-10 \mathrm{~min}$, the digest was washed and explanted into culture dishes allowing cellular attachment (Nunclon $90 \mathrm{~mm} \emptyset$; Nunc, Kamstrup, Denmark). During the first $24 \mathrm{~h}$ the culture medium consisted of serum-free RPMI 1640 ( $11.1 \mathrm{mM}$ glucose; Flow Laboratories) with addition of $10 \mathrm{mM}$ nicotinamide (Sigma Chemical Co., St. Louis, MO). The cultures were then supplemented with $10 \%$ human serum (vol/vol) (The Blood Center, Huddinge Hospital, Huddinge, Sweden). The culture dishes were kept at $37^{\circ} \mathrm{C}$ in a gas phase consisting of $5 \% \mathrm{CO}_{2}$ in humidified air, and the culture medium was changed every second day. On day 4 of culture, most of the islet-like cell clusters (ICC) were free floating or could be easily detached by gentle flushing with culture medium. Free-floating fragments with a diameter $<0.7$ $\mathrm{mm}$ were considered to be ICC and were harvested without any further purification step.

At the time of transplantation, the islets or ICC were implanted through an incision in the left renal capsule of avertin-anesthetized normoglycemic B6 mice (14). In some experiments (groups F-H below), islets from different donor species or strains were carefully mixed in a culture dish before transplantation. Islets were injected by means of a glass braking pipette, and the capsulotomy was left unsutured. A total of eight recipient animal groups were designated as follows: $(a)$ B6 mice transplanted with 150 B6 islets; $(b)$ B6 mice transplanted with 150 BKs islets; $(c)$ B6 mice transplanted with 150 rat islets; $(d)$ B6 mice transplanted with 150 porcine ICC; $(e) \mathrm{B} 6(\mathrm{nu} / \mathrm{nu}$ ) mice transplanted with 150 porcine ICC; $(f)$ B6 mice transplanted with 150 B6 islets mixed with 150 BKs islets; $(g)$ B6 mice transplanted with 150 B6 islets mixed with 150 rat islets; and $(h)$ B6 mice transplanted with 150 B6 islets mixed with 150 porcine ICC.
Light microscopical examinations. Animals were killed 2 or 6 wk after transplantation. The transplant-bearing kidney was dissected free from blood vessels and fat. The islet graft, clearly visible as a whitish spot under the renal capsule, was excised with a margin of $\sim 3 \mathrm{~mm}$, fixed in Bouin's solution, and embedded in paraffin. $7-\mu \mathrm{m}$ thick sections were stained with hematoxylin and eosin and examined in a light microscope. Some of the sections were stained for the presence of insulin by the peroxidase-antiperoxidase technique (15). Guinea pig antibodies against insulin were obtained from Bio-Yeda (Rehovot, Israel). The second antibody and peroxidase-antiperoxidase complex were from Dakopatts (Glostrup, Denmark). The specificity of the immunostaining was tested by omission of the primary antibody and by application of the primary antibody blocked with insulin.

Insulin and DNA contents of the islet grafts. These determinations were made only in animals killed 6 wk after transplantation. The graft was removed from the kidney as previously described (14), and sonicated in $200 \mu \mathrm{l}$ of redistilled water. Duplicate $25-\mu \mathrm{l}$ samples were analyzed by fluorophotometry for DNA content $(16,17)$. A total of $375 \mu \mathrm{l}$ acid-ethanol $(0.18 \mathrm{M} \mathrm{HCl}$ in $95 \%$ (vol/vol ethanol) was added to the remaining homogenate. The samples were extracted overnight at $4^{\circ} \mathrm{C}$, followed by radioimmunological assay of insulin (18).

Perfusion of graft-bearing kidneys. These studies were performed 2 or $6 \mathrm{wk}$ after transplantation. The technique has previously been described in detail (14). Briefly, the transplant-bearing kidney was removed together with parts of the aorta and inferior vena cava. Both the ureter and renal vein were cut, while the aorta was cannulated and infused with a continuously gassed $\left(\mathrm{O}_{2} / \mathrm{CO}_{2}=95: 5\right) \mathrm{Krebs}-\mathrm{Ringer}$ bicarbonate buffer (19) supplemented with $2.0 \%$ (wt/vol) each of bovine serum albumin (Fraction V; Miles Laboratories, Slough, United Kingdom), Dextran T70 (Pharmacia Fine Chemicals, Uppsala, Sweden ), and 2.8 or $16.7 \mathrm{mM}$ D-glucose. The medium was administered at a rate of $1.0 \mathrm{ml} / \mathrm{min}$ without recycling for $65 \mathrm{~min}$ with a perfusion pressure of $\sim 40 \mathrm{mmHg}$.

The perfusion experiments started with a 20 -min period using a medium containing $2.8 \mathrm{mM}$ glucose, followed by 30 min with 16.7 $\mathrm{mM}$ glucose and finally $15 \mathrm{~min}$ with $2.8 \mathrm{mM}$ glucose. A $1.0-\mathrm{ml}$ sample of the effluent medium was collected every 5 th min, except for the first 10 min of perfusion after medium changes when samples were taken after 1-5, 7, and $10 \mathrm{~min}$. The insulin concentrations of these samples were measured by radioimmunoassay. The rate of insulin secretion was calculated by multiplying the insulin concentration in the sample by the flow rate, giving values expressed as nanograms of insulin per minute. The total stimulated insulin response to glucose of the grafts was obtained by planimetry of the areas for each individual perfusion curve. During perfusion with $16.7 \mathrm{mM}$ glucose, areas were measured separately during the first $7 \mathrm{~min}$ and during the next $23 \mathrm{~min}$ to evaluate the first and second phases of insulin secretion separately.

\section{Results}

All animals tolerated the transplantation procedure without any signs of infirmity. The syngeneic grafts in group A could easily be identified macroscopically 2 or 6 wk after transplantation as an homogenous whitish spot under the renal capsule. In groups B, C, and D, only fibrous scar tissue could be seen at the site of implantation 6 wk after implantation, whereas in mixed islet grafts (groups F, G, and H), the islet tissue was scattered between strands of fibrotic tissue.

Light microscopical examination (Fig. 1). 2 wk after transplantation endocrine cells were seen in all animals implanted with syngeneic islets (group A). Immunohistochemical staining of insulin confirmed the presence of a majority of intensely stained insulin-positive cells. In a few transplants, mononuclear cells were seen in the area between the islet graft and kidney parenchyma. However, at no occasion were mononuclear cells seen to penetrate into the transplant. Grafts obtained 

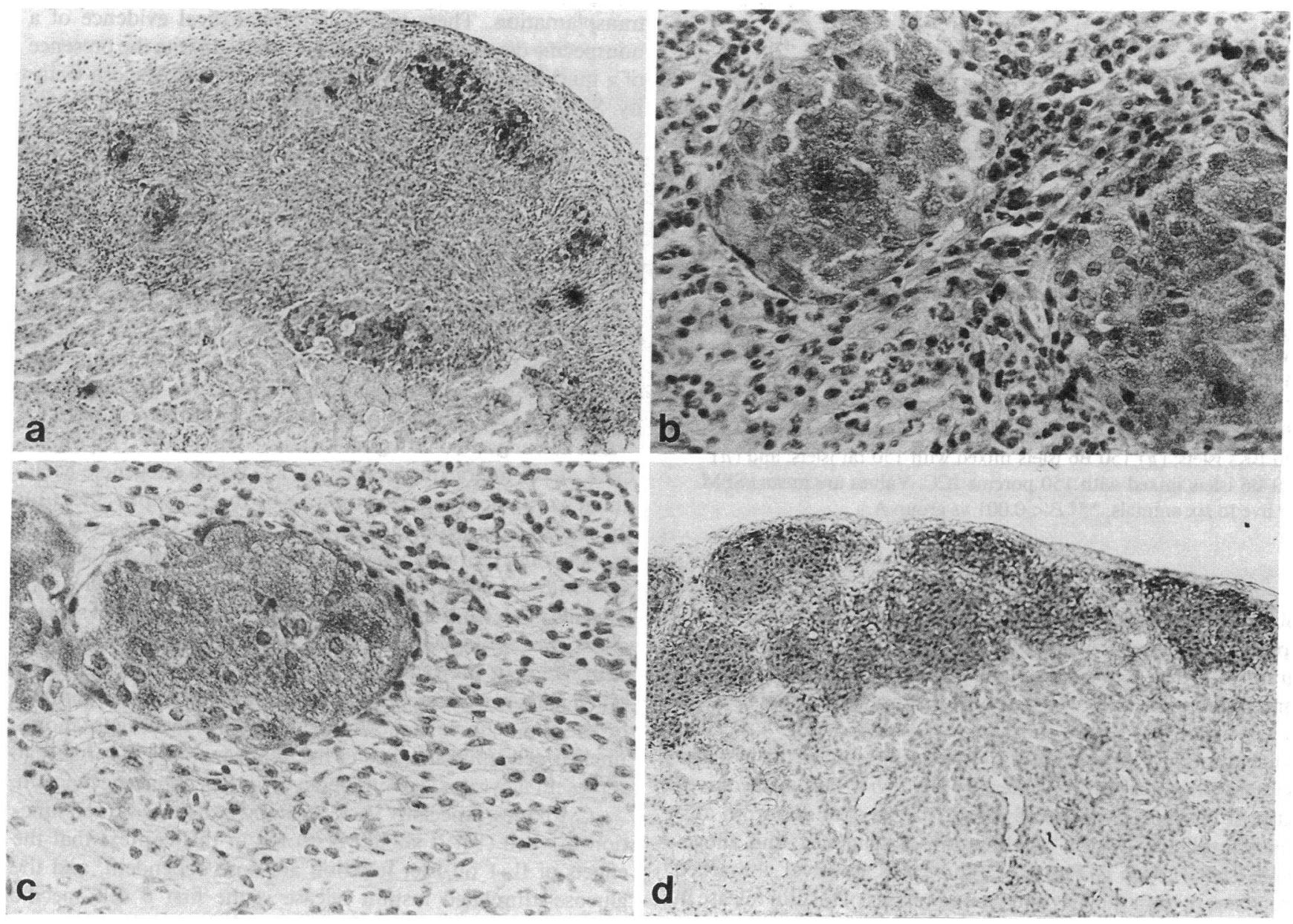

Figure 1. Light micrographs of mixed syngeneic-xenogeneic islet grafts implanted under the renal capsule of C57BL/6 mice. The sections were immunocytochemically stained for insulin (cells with dark cytoplasm). (a) A mixed transplant consisting of 150 syngeneic mouse islets and 150 fetal isletlike cell clusters $2 \mathrm{wk}$ after implantation. Scattered islets with preserved insulin immunoreactivity can be seen surrounded by a dense mononuclear cell infiltrate. $\times 100$. $(b)$ High power view of the same transplant as in $a$. Two islets that contain a majority of insulin-positive cells and a few peripheral cells devoid of insulin immunoreactivity can be seen. A dense mononuclear cell infiltrate, which does not penetrate the islet capsule, is present around the islets. $\times 460$. (c) High power micrograph of a mixed transplant consisting of 150 syngeneic mouse islets and 150 rat islets $2 \mathrm{wk}$ after implantation. The same morphological appearance as in $b$ can be observed. $\times 460$. (d) A mixed transplant consisting of 150 syngeneic mouse islets and 150 rat islets $6 \mathrm{wk}$ after implantation. The graft contains mainly insulin-immunoreactive islets with sparse fibrous tissue. The renal cortex can be seen in the lower part of the figure. $\times 100$.

from animals receiving either allogeneic or concordant/discordant xenogeneic islet grafts (groups B, C, and D) displayed an intense mononuclear cell infiltration, which completely covered the transplant. Also necrotic areas were regularly seen within these grafts, and only a few insulin-positive cells were observed. The mixed islet grafts (groups F, G, and $\mathrm{H}$ ) were composed of scattered intact islets, in which no cellular infiltration could be seen, surrounded by a large number of mononuclear cells, which covered the remaining parts of the graft (Fig. $1 a-c)$. Insulin staining revealed a large number of insulinpositive cells within the intact islets, but only few in the regions containing mononuclear cells.

Grafts obtained $6 \mathrm{wk}$ after transplantation containing syngeneic islets, either alone (group A) or mixed with allogeneic or xenogeneic islets (groups F, G, and $\mathrm{H}$ ) consisted of intact islet tissue, which stained intensely for insulin. The mixed islet grafts also contained clusters of mononuclear cells in the region between the basal part of the islet graft and the kidney parenchyma (Fig. $1 d$ ). Fibrous scar tissue with no vestiges of endo- crine cells was observed in grafts removed from animals transplanted with only allogeneic or concordant/discordant xenogeneic islets (group B, C, and D).

Insulin and DNA content of the islet graft (Figs. 2 and 3). No significant differences in insulin contents of the islet grafts were observed between the syngeneic islet grafts in group $A$ and the mixed islets grafts in groups $F, G$, and $H$. Transplants removed from animals implanted either with ICC, BKs, or rat islets alone (groups B, C, and D) contained only minute amounts of insulin, which were close to the detection limit of the radioimmunoassay. Fetal porcine ICC transplanted to nude B6 mice (group E) had an insulin content that was two to three times that measured in group $A$.

The DNA content of the BKs islet grafts (group B) and in the mixed islet grafts (groups $\mathrm{G}, \mathrm{H}$, and $\mathrm{F}$ ) was significantly increased when compared with group A. Also, the ICC transplanted to nude B6 mice (group E) had an increased DNA content, while pure xenogeneic grafts contained similar amounts of DNA as group A. 


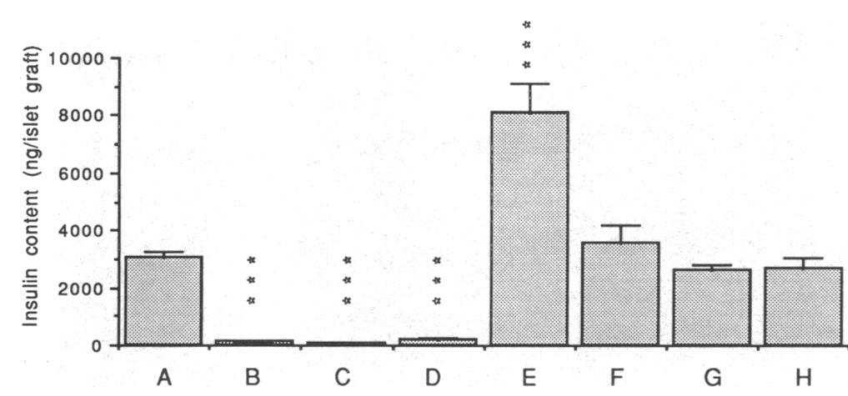

Figure 2. Graft insulin contents of islet grafts $6 \mathrm{wk}$ after transplantation under the kidney capsule of athymic B6 ( $\mathrm{nu} / \mathrm{nu}$ ) mice (group E) or B6 mice (other groups). Islet grafts were originally composed of either (a) 150 B6 islets; (b) 150 BKs islets; (c) 150 rat islets; $(d)$ 150 porcine ICC; $(e) 150$ porcine ICC; $(f) 150$ B6 islets mixed with 150 BKs islets; $(g) 150$ B6 islets mixed with 150 rat islets; and $(h)$ 150 B6 islets mixed with 150 porcine ICC. Values are mean \pm SEM for five to six animals. ${ }^{* * *} P<0.001$ vs group $\mathrm{A}$.

Perfusion experiments (Figs. 4 and 5). 2 wk after transplantation, a pronounced first peak of insulin release in response to a glucose stimulus was observed from the syngeneic grafts in group A. This was followed by a slightly smaller second phase of insulin release, which promptly returned to basal levels when the glucose stimulus was removed (Fig. $4 a$ ). The total amount of secreted insulin was similar during the first and second phases of insulin release (Fig. $4 \mathrm{~b}$ ). Perfusion curves almost identical to those of group A were obtained from animals implanted with a combination of syngeneic and allogeneic islets (group F, Fig. $4 a$ ). There was, however, a marked decrease in both the first and second phases of insulin release in groups $\mathrm{G}$ and $\mathrm{H}$ ( Fig. 4, $a$ and $b$, mixed syngeneic and xenogeneic islets).

The first phase insulin release from syngeneic grafts $6 \mathrm{wk}$ after transplantation (group A) was similar to that observed in animals perfused $2 \mathrm{wk}$ after implantation, but the magnitude of the second phase had increased almost 100\% (Fig. 5, $a$ and $b$ ). The insulin release from mixed grafts in groups $F$ and $G$ were similar to that of group A (Fig. $5 b$ ). However, mixed syngeneic-discordant xenogeneic grafts (group $\mathrm{H}$ ) had a normal first phase insulin release, but a markedly reduced second phase insulin release (Fig. 5, $a$ and $b$ ).

In all perfusion experiments insulin release returned to basal values, which were close to or below the detection limit of the radioimmunoassay for insulin, whenever the medium glucose concentration was lowered to $2.8 \mathrm{mM}$.

\section{Discussion}

In normoglycemic ánimals, there is a close and highly significant correlation between pancreatic insulin content and $\beta$ cell volume (20), and it is likely that this is the case also for transplanted islets of Langerhans (11). In the present study, transplants removed from mice implanted with only porcine ICC, rat, or BKs islets contained only minute amounts of insulin, whereas no differences in insulin content could be observed between the mixed islet grafts and the pure syngeneic islet grafts $6 \mathrm{wk}$ after transplantation. These findings suggest that the syngeneic islets remain intact, and that the mechanism of both allograft and xenograft rejection is highly specific. Furthermore, the rejection process seems to be completed $6 \mathrm{wk}$ after transplantation. There was no morphological evidence of a nonspecific destruction of syngeneic islets, despite the presence of a marked mononuclear cell infiltration in their close vicinity. Similar results have previously been reported with mixed syngeneic and allogeneic rat islets (11). These results were interpreted to support the view of an infiltration with mainly cytotoxic $T$ cells in the islet graft, whereas the data were considered to be incompatible with the presence of a nonspecific immune destruction, such as a delayed type of hypersensitivity reaction. Since, in the present study, the insulin content of the mixed syngeneic-xenogeneic islet grafts did not differ from that of syngeneic islets implanted alone, the rejection of isolated xenogeneic islets also seems to occur by mechanisms quite as specific as those mediating allograft rejections. There is so far only limited knowledge on the cellular immune responses towards a xenograft, although it is believed that $\mathrm{CD4} 4^{+} \mathrm{T}$ lymphocytes are of major importance $(7,8)$. While allogeneic MHC antigens can be recognized directly by the $T$ lymphocytes (1), the recognition of xenogeneic MHC antigens seems to require that peptides of the xenogeneic MHC are presented in association with the MHC complex of the responding species (7). This notion is further supported by the identification of specific oligopeptides of xenogeneic MHC class I antigen in association with recipient MHC molecules $(21,22)$. However, this combined antigen (xenopeptide and recipient MHC) is not present on the parenchymal xenogeneic cells. Thus, the intense mononuclear cell infiltrate among the xenogeneic islets is likely to represent a cytotoxic $T$ lymphocyte-independent mechanism.

Cytokines, especially IL-1, are known to impair $\beta$ cell function in vitro (9). It should be noted in this context that the effects of IL-1 on islet function are dose dependent, and the glucose-stimulated insulin release is the first $\beta$ cell-specific function to be adversely affected already by low IL-1 concentrations in vitro (23). IL-1 is released from activated macrophages, and one of its functions is to activate $\mathrm{T}$ lymphocytes that have bound to the antigen-MHC complex on an antigenpresenting cell ( 3 ). The release of cytokines within a rejecting allograft was recently investigated in kidneys (24) and livers (25). Cytokines that are thought to contribute to nonspecific lymphoid infiltration, such as IL- $1 \beta$, IL-6, and TNF- $\alpha$, were regularly observed in the implants. In most rejecting kidney allografts, mRNA for both IL-2R, IL-4, and IL-5 were present, implying that these cytokines play an important role in ongoing allograft rejections, whereas mRNA for IL-2, IL-7, and IFN $-\mu$ were detected only rarely. However, a transient expres-

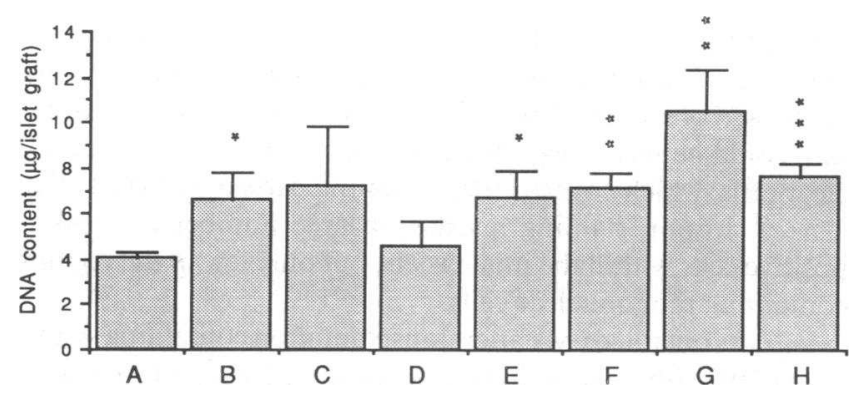

Figure 3. Graft DNA contents of islet grafts $6 \mathrm{wk}$ after transplantation under the kidney capsule of athymic B6 ( $\mathrm{nu} / \mathrm{nu}$ ) mice (group E) or B6 mice (other groups). Groups are defined as in Fig 2. Values are mean \pm SEM for five to six animals. ${ }^{*} P<0.05,{ }^{* *} P<0.01$, and ${ }^{* * *} P$ $<0.001$ vs group $\mathrm{A}$. 

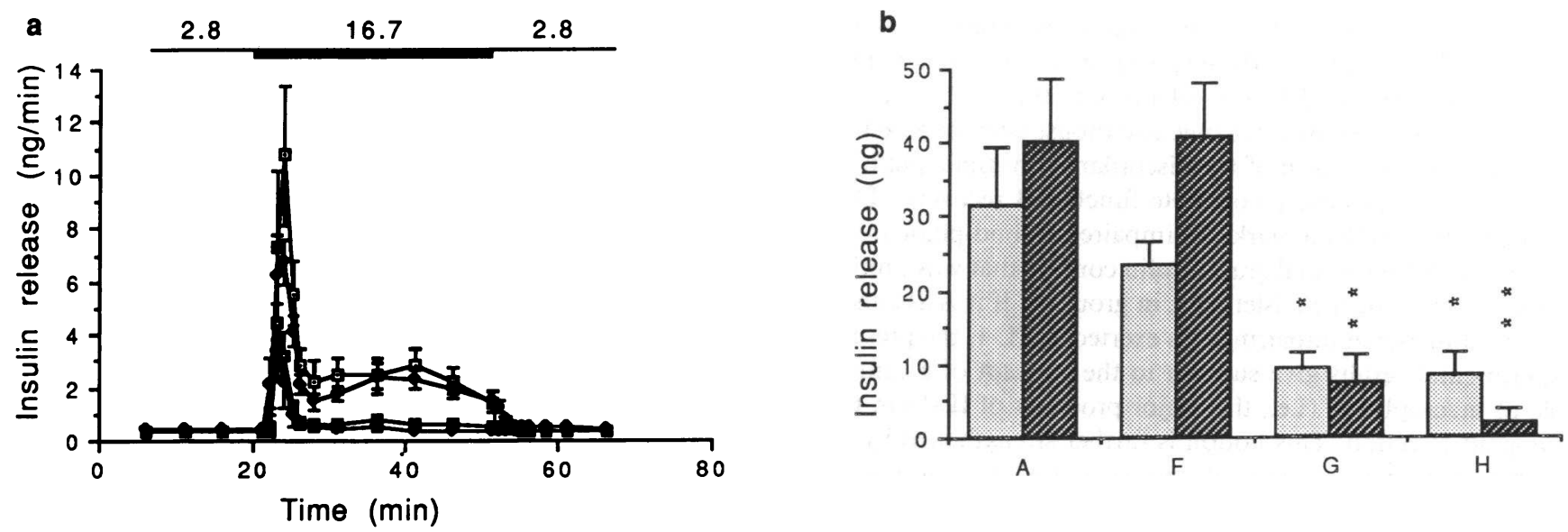

Figure 4. (a) Insulin concentrations in the effluent medium collected from islet graft-bearing kidneys of B6 mice. Kidneys were perfused 2 wk after transplantation with medium containing 2.8 or $16.7 \mathrm{mM}$ glucose as indicated at the top of the figure. All animals were transplanted with 150 syngeneic mouse islets, either alone (group A, open squares), or mixed with 150 allogeneic mouse islets (group F, filled triangles), 150 rat islets (group G, filled squares), or 150 porcine ICC (group H, filled diamonds). Values are mean \pm SEM for five to six animals. ( $b$ ) Total stimulated insulin secretion from islet grafts $2 \mathrm{wk}$ after implantation. Insulin release was measured separately during the first $7 \mathrm{~min}($ dotted bars), and during the next $23 \mathrm{~min}$ (hatched bars). Groups are defined as in Fig 2 . Values are mean \pm SEM for five to six animals. ${ }^{*} P<0.05$ and ${ }^{* *} P$ $<0.01$ vs group A.

sion of IL-2 and IFN- $\mu$ seems to precede the cellular infiltration in both kidney (26) and islet (27) allograft rejection. Furthermore, a local release of IFN- $\mu$ and probably also TNF- $\alpha$ may be of importance to increase the intrinsically low MHC antigen expression on islet tissue, thereby rendering islet cells more vulnerable to $\mathrm{CD}^{+} \mathrm{T}$ lymphocytes (28). Based on this, it can be assumed that a large number of cytokines were locally produced within the allograft also in this model of mixed islet grafts, although no actual measurements of these substances were performed in the present study.

Thus, although the syngeneic mouse islets within the grafts are unlikely to be a primary target for the immunological at- tack, they may nevertheless be exposed to cytokines; e.g., IL-1 released during the allograft rejection in their close vicinity. However, no adverse effects on the syngeneic islets could be detected. The insulin secretion from the mixed syngeneic-allogeneic grafts during the morphologically very intense allograft rejection ( 2 wk after implantation) or after the completed rejection process (6 wk after implantation) was not different when compared with the grafts consisting only of syngeneic mouse islet. In contrast, a pronounced impairment of both the first and second phases of insulin release was observed 2 wk after implantation in grafts composed of mixed syngeneic-xenogeneic islets. When the mixed islet grafts were perfused after
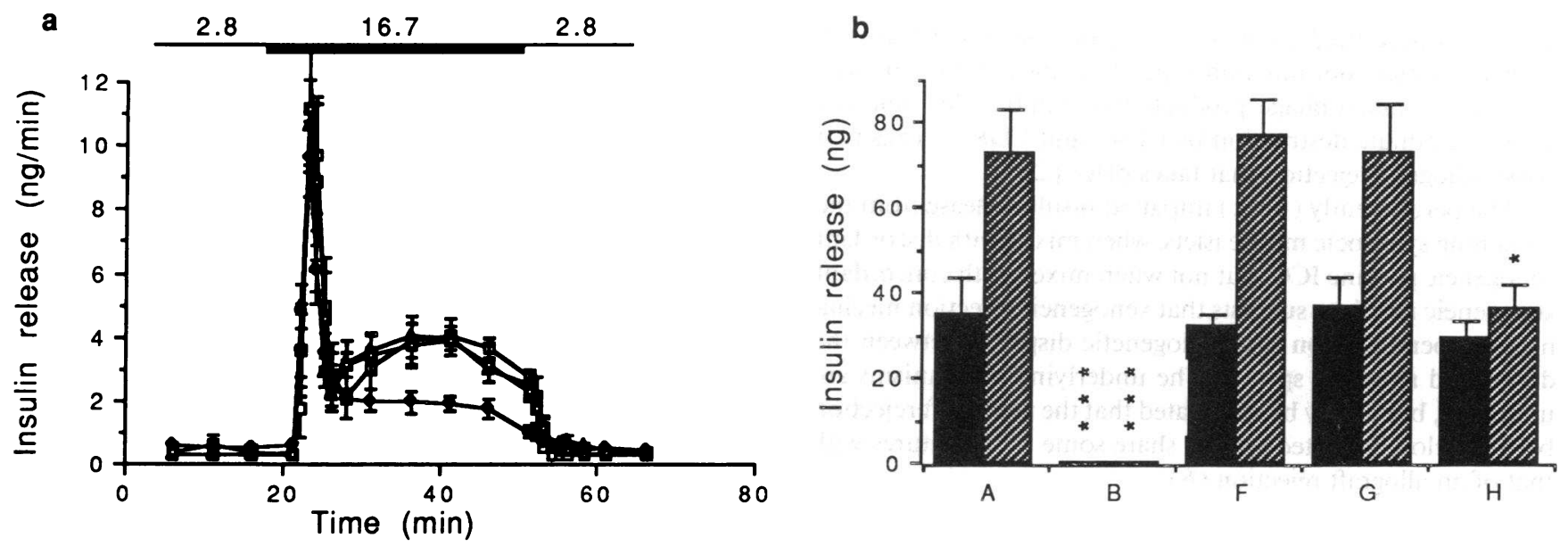

Figure 5. (a) Insulin concentrations in the effluent medium collected from islet graft-bearing kidneys of B6 mice. Kidneys were perfused 6 wk after transplantation with medium containing 2.8 or $16.7 \mathrm{mM}$ glucose as indicated at the top of the figure. All animals were transplanted with 150 syngeneic mouse islets, either alone (group A, open squares), or mixed with 150 allogeneic mouse islets (group F, filled triangles), 150 rat islets (group G, filled squares), or 150 porcine ICC (group H, filled diamonds). Values are mean \pm SEM for animals. (b) Total stimulated insulin secretion from islet grafts $6 \mathrm{wk}$ after implantation. Insulin release were measured separately during the first 7 min (filled bars) and during the next 23 min (hatched bars). Groups are defined as in Fig 2 . Values are mean \pm SEM for five to six animals. ${ }^{*} P<0.05$ and ${ }^{* * *} P<0.001$ vs group A. 
the completed rejection of the concordant xenogeneic rat islets ( 6 wk after implantation), the insulin release from the remaining syngeneic mouse islets were identical to that of the control grafts in group A. However, syngeneic mouse islets exposed to the rejection mechanism of the discordant xenogenic pig ICC were unable to achieve a complete functional recovery. This was demonstrated by a markedly impaired second-phase insulin release, despite a total graft insulin content that was similar to that of the syngeneic islet graft in group A. If it is assumed that this functional impairment is exerted by IL-1, the present experimental results give support to the concept of a central role of macrophages (i.e., the major producer of IL-1) in the xenograft rejection. This notion is further strengthened by an immunohistological study of the xenograft rejection after transplantation of fetal pig proislets to $\mathrm{CBA} / \mathrm{H}$ mice (5). The intense cellular infiltrate consisted predominantly of eosinophils, macrophages, and CD4 ${ }^{+} \mathrm{T}$ lymphocytes, with only small numbers of $\mathrm{CD}^{+} \mathrm{T}$ cells being present. Likewise, the absence of a detrimental effect on the syngeneic islets, when mixed with allogeneic islets, is in accordance with previous immunohistological characterization of the cellular infiltrate in classic allograft rejections, which consist mainly of $\mathrm{Thy}-1^{+}, \mathrm{CD}^{+}$, $\mathrm{CD}^{+}$, and IL2- $\mathrm{R}^{+} \mathrm{T}$ cells with a relative paucity of macrophages (29). It should also be noted that during a number of clinical and experimental conditions, there is evidence that macrophages or products released from these cells are associated with $\beta$ cell dysfunction. First, in vitro coculture of macrophages and mouse pancreatic islets resulted in inhibition of $\beta$ cell function and cell death (30). It was subsequently shown that IL-1 (31) or nitric oxide (32) released from the macrophages could be associated with this dysfunction. Furthermore, a functional impairment of the $\beta$ cell responsiveness to a glucose stimulus has been demonstrated in early stages of type 1 diabetes mellitus in humans (33), as well as in the two most studied experimental models of autoimmune diabetes mellitus, namely BB rats (34) and NOD mice (35). In the development of autoimmune diabetes mellitus there is initially an intense infiltration of mononuclear cells within the islets of Langerhans, one of the first to appear being the macrophage (36-38). Interestingly, it was recently demonstrated that islet allograft primary nonfunction depends on the presence of macrophages or macrophage products that inhibit islet function until an ultimate destruction by $\mathrm{CD} 4^{+}$and $\mathrm{CD} 8^{+} \mathrm{T}$ cells in a classic allograft rejection that takes place (29).

The permanently ( $6 \mathrm{wk}$ ) impaired insulin release from the remaining syngeneic mouse islets, when mixed with discordant xenogeneic porcine ICC, but not when mixed with concordant xenogeneic rat islets, suggests that xenogeneic rejection mechanisms depend also on the phylogenetic disparity between the donor and recipient species. The underlying mechanisms are unknown, but it may be speculated that the xenograft rejection between closely related species share some of its features with that of an allograft rejection (6).

\section{Acknowledgments}

The skilled technical assistance of Birgitta Bodin and Astrid Nordin is gratefully acknowledged. The study was supported by grants from the Swedish Medical Research Council (12X-109 and 12P-9287), the Nordic Insulin Fund, Svenska Barndiabetes Fonden, the Swedish Hoechst Diabetes Fund, the Swedish Diabetes Association, the Swedish Society for Medical Research, the Ernfors Family Fund, and the Juvenile Diabetes Foundation International.

\section{References}

1. Lechler, R. I., G. Lombardi, J. R. Batchelor, N. Reinsmoen, and F. H. Bach. 1990. The molecular basis of alloreactivity. Immunol. Today. 11:83-88.

2. Stock, P. G., N. L. Ascher, S. Chen, J. Field, F. H. Bach, and D. E. R. Sutherland. 1991. Evidence for direct and indirect pathways in the generation of the alloimmune response against pancreatic islets. Transplantation (Baltimore). 52:704-709.

3. Weaver, C. T., and E. R. Unanue. 1990. The costimulatory function of antigen presenting cells. Immunol. Today. 11:49-55.

4. Pierson, R. N., H. J. Winn, P. S. Russell, and H. J. Auchincloss. 1989. Xenogeneic skin graft rejection is especially dependent on CD4 ${ }^{+} \mathrm{T}$ cells. J. Exp. Med. 170:991-996.

5. Simeonovic, C. J., R. Ceredig, and J. D. Wilson. 1990. Effect of GK 1.5 monoclonal antibody dosage on survival of pig proislet xenografts in CD4 ${ }^{+} \mathrm{T}$ cell-depleted mice. Transplantation (Baltimore). 49:849-856.

6. Auchincloss, H. J. 1988. Xenogeneic transplantation. Transplantation (Baltimore). 46:1-20.

7. Auchincloss, H. 1990. Xenografting: a review. Transplant. Rev. 4:14-27.

8. Sachs, D. H., and F. H. Bach. 1990. Immunology of xenograft rejection. Human Immunol. 28:245-251.

9. Sandler, S., D. L. Eizirik, C. Svensson, E. Strandell, M. Welsh, and N. Welsh. 1991. Biochemical and molecular actions of interleukin-1 on pancreatic $\beta$-cells. Autoimmunity. 10:241-253.

10. Mandrup-Poulsen, T., S. Helqvist, J. Molvig, L. D. Wogensen, and J. Nerup. 1989. Cytokines as immune effector molecules in autoimmune endocrine diseases with special reference to insulin dependent diabetes mellitus. Autoimmunity. 4:191-218.

11. Sutton, R., D. W. R. Gray, P. McShane, M. J. Dallman, and P. J. Morris. 1989. The specificity of rejection and the absence of susceptibility of pancreatic islets $\beta$ cells to nonspecific immune destruction in mixed strain islets grafted beneath the renal capsule in the rat. J. Exp. Med. 170:751-762.

12. Howell, S. L., and K. W. Taylor. 1968. Potassium ions and the secretion of insulin by the islets of Langerhans incubated in vitro. Biochem J. 108:17-24.

13. Korsgren, O., S. Sandler, A. S. Landström, L. Jansson, and A. Andersson. 1988. Large-scale production of fetal porcine pancreatic isletlike cell clusters. An experimental tool for studies of islet cell differentiation and xenotransplantation. Transplantation (Baltimore). 45:509-514.

14. Korsgren, O., L. Jansson, S. Sandler, and A. Andersson. 1990. Hyperglycemia-induced B cell toxicity. The fate of pancreatic islets transplanted into diabetic mice is dependent on their genetic background. J. Clin. Invest. 75:2047-2055.

15. Sternberger, L., P. H. Hardy, J. J. Cuculis, and H. G. Meyer. 1970. The labelled antibody enzyme method of immunohistochemistry. J. Histochem. Cytochem. 18:315-333.

16. Kissane, J. M., and E. Robins. 1958. The fluorometric measurements of deoxyribonucleic acid in animal tissues with special reference to the central nervous system. J. Biol. Chem. 233:184-188.

17. Hinegardner, R. T. 1971. An improved fluorometric assay for DNA. Anal. Biochem. 39:197-201.

18. Heding, L. G. 1972. Determination of total serum insulin (IRI) in insulintreated diabetic patients. Diabetologia. 8:260-268.

19. Krebs, H. A., and K. Henseleit. 1932. Untersuchungen über die Harnstoffbildung im Tierkörper. Hoppe-Seyler's Z. Physiol. Chem. 210:33-66.

20. McEvoy, R. C. 1981. Changes in the volumes of the A-, B-, and D-cell populations in the pancreatic islets during the postnatal development of the rat. Diabetes. 30:813-817.

21. Maryanski, J. L., P. Pala, G. Corradin, B. R. Jordan, and J. Cerottini 1986. H-2-restricted cytolytic T cells specific for HLA can recognize a synthetic HLA peptide. Nature (Lond.). 324:578-580.

22. Gress, R. E., S. G. Nathenson, and P. J. Lucas. 1989. Fine specificity of xenogeneic antigen recognition by human $\mathrm{T}$ cells. Transplantation (Baltimore). 48:93-98.

23. Leiter, E. H. 1987. Murine macrophages and pancreatic $\beta$ cell. Chemotactic properties of insulin and $\beta$-cytostatic action of interleukin-1. J. Exp. Med. 166:1174-1179.

24. Krams, S. M., D. A. Falco, J. C. Villanueva, J. Rabkin, S. J. Tomlanovich F. Vincenti, W. J. C. Amend, J. Melzer, M. R. Garovoy, J. P. Roberts, N. L. Ascher, and O. M. Martinez. 1992. Cytokine and T cell receptor gene expression at the site of allograft rejection. Transplantation (Baltimore). 53:151-156.

25. Martinez, O. M., S. M. Krams, M. Sterneck, J. C. Villanueva, D. A. Falco, L. D. Ferrell, J. Lake, J. P. Roberts, and N. L. Ascher. 1992. Intragraft cytokine profile during human liver allograft rejection. Transplantation (Baltimore). 53:449-456.

26. Dallman, M. J., J. Roake, D. Hughes, G. Toogood, and P. J. Morris. 1992. Sequential analysis of IL-2 gene transcription in renal transplants. Transplanta tion (Baltimore). 53:683-685. 
27. O’Connell, P. J., A. Pacheco-Silva, P. W. Nickerson, R. A. Muggia, M. Bastos, V. R. Kelley and T. B. Strom. Unmodified pancreatic islet allograft rejection results in preferential expression of certain T cell activation transcripts. $J$. Immunol. 150:1093-1104.

28. Hao, L., Y. Wang, R. G. Gill, F. G. Rosa, D. W. Talmage, and K. J. Lafferty. 1990. Role of lymphokine in islet allograft rejection. Transplantation (Baltimore). 49:609-614.

29. Kaufman, D. B., J. L. Platt, F. L. Rabe, D. L. Dunn, F. H. Bach, and D. E. R. Sutherland. 1990. Differential roles of Mac-1 ${ }^{+}$cells, and $\mathrm{CD}^{+}$and CD8 ${ }^{+} \mathrm{T}$ lymphocytes in primary nonfunction and classic rejection of islet allografts. J. Exp. Med. 172:291-302.

30. Schwizer, R. W., E. H. Leiter, and R. Evans. 1984. Macrophage mediated cytotoxicity against cultured pancreatic islet cells. Transplantation (Baltimore). 37:539-544.

31. Mandrup-Poulsen, T., K. Bendtzen, J. Nerup, C. A. Dinarello, M. Svenson, and J. H. Nielsen. 1986. Affinity-purified human interleukin 1 is cytotoxic to islet cells of Langerhans. Diabetologia. 29:63-67.

32. Kroncke, K. D., V. Kolb-Bachofen, B. Berschick, V. Burkart, and H. Kolb. 1991. Activated macrophages kill pancreatic syngeneic islet cells via arginine-dependent nitric oxide generation. Biochem. Biophys. Res. Commun. 175:752-758.
33. Ganda, O. P., S. Srikanta, S. J. Brink, M. A. Morris, R. E. Gleason, J. S. Soeldner, and G. S. Eisenbarth. 1984. Differential sensitivity to $\beta$-cell secretagogues in "early" type 1 diabetes mellitus. Diabetes. 33:516-521.

34. Grill, V., and L. Herberg. 1983. Glucose- and arginine-induced insulin and glucagon responses from the isolated perfused pancreas of the BB-Wistar diabetic rat: evidence for selective impairment of glucose regulation. Acta Endocrinol. 102:561-566.

35. Kano, Y., T. Kanatsuna, N. Nakamura, Y. Kitagawa, H. Mori, S. Kajiyama, K. Nakano, and M. Kondo. 1986. Defect of the first-phase insulin secretion to glucose stimulation in the perfused pancreas of the nonobese diabetic (NOD) mouse. Diabetes. 35:486-490.

36. Lee, K. U., K. Amano, and J. W. Yoon. 1988. Evidence for initial involvement of macrophages in development of insulitis in NOD mice. Diabetes 37:989-991.

37. Hanenberg, H., V. Kolb-Bachofen, G. Kantwerk-Funke, and H. Kolb. 1989. Macrophage infiltration precedes and is a prerequisite for lymphocytic insulitis in pancreatic islets of pre-diabetic BB rats. Diabetologia. 32:126-134.

38. Roep, B. O., A. A. Kallan, and R. R. P. De Vries. 1992. $\beta$-cell antigen-specific lysis of macrophages by CD4 T-cell clones from newly diagnosed IDDM patient. Diabetes. 41:1380-1384. 